\title{
Divulgações de informações e o efeito no retorno de ações da maior empresa de educação listada na B3 (Brasil, Bolsa, Balcão)
}

\author{
Information disclosures and the effect on the return of stocks of the largest education \\ company listed on B3 (Brasil, Bolsa, Balcão)
}

Divulgaciones de información y el efecto en el retorno de acciones de la mayor empresa de educación listada en B3 (Brasil, Bolsa, Balcão)

\section{Liliane Vicentina Gomes}

Mestranda em Administração na Pontifícia Universidade Católica de São Paulo (PUC-SP)

Endereço: Rua Monte Alegre, 984, Perdizes

CEP: 05014-901 - São Paulo/SP - Brasil

E-mail: lilianevgomes@hotmail.com

Telefone: (11) 99526-2359

\section{José Odálio dos Santos}

Livre docente em Administração na Universidade de São Paulo (USP)

Professor da Pontifícia Universidade Católica de São Paulo (PUC-SP)

Endereço: Rua Monte Alegre, 984, Perdizes

CEP: 05014-901 - São Paulo/SP - Brasil

E-mail: jodalio569@gmail.com

Telefone: (11) 99113-4631

\section{Cristiane Lana Silva}

Mestranda em Administração na Pontifícia Universidade Católica de São Paulo (PUC-SP)

Endereço: Rua Monte Alegre, 984, Perdizes

CEP: 05014-901 - São Paulo/SP - Brasil

E-mail: lana2427@gmail.com

Telefone: (11) 98505-3249

\section{Maurício Ferreira de Souza}

Mestrando em Ciências Contábeis na Pontifícia Universidade Católica de São Paulo (PUC-SP) Endereço: Rua Monte Alegre, 984, Perdizes

CEP: 05014-901 - São Paulo/SP - Brasil

E-mail: mauricio.souza@redegt.com.br

Telefone: (21) 98733-9488

Artigo recebido em 25/01/2018. Revisado por pares em 08/05/2018. Reformulado em 30/05/2018. Recomendado para publicação em 28/09/2018 por Carlos Eduardo Facin Lavarda (Editor-Chefe). Publicado em 19/12/2018. 


\section{Resumo}

O mercado é eficiente se novas informações relevantes causarem variação no retorno das ações. As ações podem ser afetadas por eventos e isso pode causar oscilações. A pesquisa analisa a reação do mercado à divulgação de informações sobre a maior instituição de educação listada na B3. Foi utilizado o estudo de eventos para confrontar o comportamento do retorno das ações no período de 30 de setembro 2015 a 30 de setembro de 2017. A pesquisa parte da teoria de mercado eficiente. As informações selecionadas foram distribuídas em grupos, sendo: A Divulgação dos resultados trimestrais; B - Operações de compra e venda de participações; C Mudanças relacionadas ao Financiamento Estudantil. Os resultados evidenciaram que a reação que caracterizou o fator mercado eficiente foi identificada no Grupo C, em parte corroborada pelo comportamento do preço da ação.

Palavras-chave: Eficiência de Mercado; Estudo de Eventos; Instituição de Ensino

\section{Abstract}

The market is efficient if new relevant information causes change in stocks returns. Stocks can be affected by events and this can cause oscillations. The paper analyzes the reaction of the market to the disclosure of information about the largest education institution listed in B3. It was used the event study to confront the behavior of the return of stocks in the period from September 30, 2015 to September 30, 2017. The research starts from efficient market theory. The selected information was distributed in groups, being: A - Disclosure of quarterly results; $B$ - Share purchase and sale transactions; $C$ - Changes related to Student Funding. The results showed that the reaction that characterized the efficient market factor was identified in Group $C$, partly corroborated by the stock price behavior.

Keywords: Efficiency Market; Event Study; Educational Institution

\section{Resumen}

El mercado es eficiente si la nueva información relevante influye en el retorno de las acciones. Las acciones pueden ser afectadas por eventos y esto puede causar oscilaciones. La investigación analiza la reacción del mercado a la divulgación de informaciones sobre la mayor institución de educación listada en la B3. Se utilizó el estudio de eventos para confrontar el comportamiento del retorno de las acciones en el período del 30 de septiembre de 2015 al 30 de septiembre de 2017. La investigación parte de la teoría de mercado eficiente. La información seleccionada fue distribuida en grupos, siendo: A - Divulgación de los resultados trimestrales; $B$ - Operaciones de compra y venta de participaciones; $C$ - Cambios relacionados con la Financiación Estudiantil. Los resultados evidenciaron que la reacción que caracterizó el factor mercado eficiente fue identificada en el Grupo C, en parte corroborada por el comportamiento del precio de la acción.

Palabras clave: Eficiencia de Mercado; Estudio de Eventos; Institucion de enseñanza

\section{Introdução}

As ações das instituições listadas em bolsa podem ser afetadas por diversos fatores sistêmicos, que podem causar oscilações no desempenho do preço e do retorno no mercado acionário. Entende-se por fatores sistêmicos os eventos não controláveis, que afetam o nível de atividade operacional e, consequentemente, a geração de fluxos de caixa da firma e dos detentores do capital patrimonial. Estes eventos estão relacionados com o comportamento de variáveis representativas dos fundamentos de mercado, como inflação, taxa de juros, paridade cambial, carga tributária, ações comerciais de concorrentes, etc. 
Para mitigar a exposição de risco na tomada de decisão, os investidores devem analisar informações inerentes a atividade operacional da empresa (ex.: gestão administrativa, produtos comercializados, clientes, fornecedores, tecnologia e governança corporativa), desempenho contábil, desempenho no mercado acionário, contexto setorial e conjuntura econômica. A eficiência de informação, ou a veracidade e qualidade da informação, é um fator importante na tomada de decisão dos investidores (GALDI et al., 2017).

Segundo Mackinley (1997), o estudo de eventos permite mensurar o efeito de um acontecimento no valor de uma empresa. Diante desse contexto, esse artigo analisa o comportamento das ações ordinárias e aborda o seguinte problema: $\mathrm{O}$ mercado reage a divulgação de informações relevantes sobre a principal instituição de ensino listada na B3 (Brasil, Bolsa, Balcão)?

Com este foco, o objetivo dessa pesquisa é investigar se a divulgação de informações relevantes influencia de forma estatisticamente significativa o comportamento dos retornos das ações ordinárias da Kroton Educacional (Kroton). Para a análise, foi selecionada a maior empresa do setor de educação listada na B3, a Kroton, por considerar sua relevância no setor que tem mostrado habilidade para transformar e induzir mudanças na sociedade (LOMBARDI et al., 2011), seus riscos específicos (ex.: regulamentação, política educacional do governo, concorrência, etc.) e seu desempenho contábil e bursátil no período de 2015 a 2017. Trata-se de um estudo de caso. Segundo Creswell (2010), o procedimento da pesquisa é de natureza descritiva e a abordagem é mista através da aquisição de indicadores quantitativos e parâmetros qualitativos de avaliação da empresa.

Ao considerar o número limitado de empresas do setor de educação superior listadas na B3 (Kroton e Estácio Participações), a diferença relevante de porte medido pelo Ativo Total em 2016 (Kroton: 17,6 bilhões; Estácio Participações: 4,1 bilhões) e, principalmente, as políticas distintas de investimento, financiamento e dividendos, considerou-se inadequada a comparação entre as empresas citadas. Optou-se, por isso, pela seleção da Kroton, que destina 97\% dos negócios para o segmento de educação superior - caso seja efetiva a transação de compra da Somos Educação em 2018, essa concentração e negócio apresentará uma alteração significativa, tendo em vista que o mercado de educação básica é $83 \%$ superior ao mercado de ensino superior. Deve-se também destacar que a escolha pela Kroton, foi influenciada pelo fato de seu valor de mercado em 2016 (R\$ 12 bilhões) representar quase o dobro do segundo grupo mundial, a chinesa New Oriental.

O objetivo principal da pesquisa é analisar se o retorno das ações ordinárias da Kroton apresentou variação estatisticamente significativa, após a divulgação de informações relevantes no mercado, relacionadas a sua atividade operacional, no período de 2015 a 2017. A operacionalização da pesquisa baseou-se na metodologia de estudo de eventos para confrontar o comportamento do retorno das ações ordinárias nos períodos ex-ante e ex-post a divulgação dos eventos selecionados. Essa é "a metodologia mais utilizada para aferir a forma semiforte, cujos testes procuram mensurar a velocidade do ajustamento dos preços dos títulos ao redor de uma data específica, quando da divulgação de informações relevantes" (CAMARGOS; BARBOSA, 2006, p. 45).

Tendo em vista os motivos citados para a seleção da empresa, associados a presença de assimetria de informações no setor, deve-se alertar que as considerações extraídas dessa pesquisa não devem ser generalizadas para outras instituições de ensino superior, tanto públicas como privadas. Além disso, o fato de haver sobreposições de eventos (EDERINGTON; GUAN, YANG, 2015) pode ser um obstáculo, pois isso pode gerar um risco de o evento influenciar os retornos (CAMARGOS; BARBOSA, 2006). Vale destacar que os investidores institucionais e especuladores também podem influenciar no preço das ações. Outrossim, a significância estatística pode não implicar em resultados práticos, por isso é necessário analisar a performance da Kroton para dar aderência ao estudo e também pode haver controvérsia sobre 
uso da metodologia de estudo de eventos (BRAV; HEATON, 2015; EDERINGTON; GUAN, YANG, 2015; BAKER, 2016) e do teste estatístico $p$-value.

O estado da arte com a realização dessa pesquisa, sustenta-se, em parte, na escassez de estudos acadêmicos com o foco proposto para o setor de educação superior, buscando elucidar o impacto das transformações no setor de ensino superior, notadamente relacionadas a entrada e suporte (gerencial e financeiro) de atores privados de grande porte na composição do capital social das empresas. Ao considerar o dinamismo do mercado acionário, essa pesquisa traz, como contribuição principal, o questionamento de existência de mercado eficiente para os investidores das ações ordinárias da Kroton, considerando o comportamento do retorno nos períodos ex-ante e ex-post à divulgação de informações relevantes no período de 2015 a 2017.

Dentre os achados da pesquisa, destaca-se a constatação de que nem todos os investidores agem da mesma forma, analisam as informações a partir de critérios técnicos semelhantes, aplicam o bom senso nas tomadas de decisão ou têm os mesmos interesses. Essa afirmação é corroborada por comportamentos não padronizados do retorno das ações diante da divulgação das informações relevantes selecionadas. Após esta introdução, o artigo está estruturado da seguinte forma: a seção 2 define a revisão da literatura, a seção 3 detalha o panorama da Kroton, a seção 4 apresenta os procedimentos metodológicos, a seção 5 mostra os resultados e a seção 6 contempla as considerações.

\section{Revisão da Literatura}

\subsection{Eficiência de Mercado}

Uma das teorias centrais na área de finanças é a Hipótese de Eficiência dos Mercados (HEM) de Fama (1970), que se apoia no modelo clássico de finanças e é derivada "do raciocínio de que o investidor é racional, avesso ao risco e que utiliza a curva de utilidade para maximizar seu bem-estar" (JUNIOR; FAMÁ, 2002, p. 25). Um dos aspectos da HEM são seus pressupostos quanto à modelagem que são baseados no comportamento:

humano racional, maximizador de utilidades e apto a processar de maneira ótima todas as informações disponíveis. Os mercados são operados por agentes de racionalidade ilimitada. Essa teoria pressupõe: competição perfeita, nenhum agente individual podendo impactar de forma significativa os preços; expectativas homogêneas, investidores totalmente informados, com acesso igualitário às informações e agindo racionalmente; ausência de fricções; ativos divisíveis e nenhum custo de transação (FAMÁ; CIOFFI; COELHO, 2008, p. 66-67).

Segundo Fama (1970), um mercado eficiente é aquele em que os preços refletem plenamente as informações disponíveis. Dessa forma, os agentes econômicos reagem com racionalidade à divulgação de dados relevantes, o mercado financeiro absorve essas informações pelas mudanças instantâneas nos preços das ações, há um reflexo do valor presente de todos os lucros atuais e futuros esperados através de um comportamento aleatório que tende a impactar o retorno (CAMPBELL, 1990; LANDSMAN; MAYDEW, 2002; KONCHITCHKI; O'LEARY, 2011; MARTIN; BORAH; PALMATIER, 2017).

Por informações relevantes, entendem-se aquelas capazes de afetar (positiva ou negativamente) o fluxo de caixa ou o desempenho futuro de uma determinada empresa e, consequentemente, a expectativa dos investidores em relação aos preços praticados no mercado (CAMARGOS; BARBOSA, 2015, p. 572).

A HEM evidencia a eficiência da informação que demonstra o quão rápido o preço da ação reflete a nova informação disponível e o quão confiável é o preço da ação no mercado em conjeturar a situação da empresa. Para Fama (1970), o mercado é eficiente quando inexiste custos de transações, toda informação existente está disponível a custo zero para todos os participantes do mercado e todos têm a mesma percepção da implicação da informação para o preço corrente e para a distribuição de preços futuros. Malkiel (2003), e Ruiz, Aké e Martínez 
(2014) supõem que o mercado é eficiente se novas informações relevantes causarem variação no retorno das ações. Há três tipos de classificações de eficiência: forte, semiforte e fraca que podem ser verificadas na Figura 1:

Figura 1: Três Formas de Eficiência de Mercado

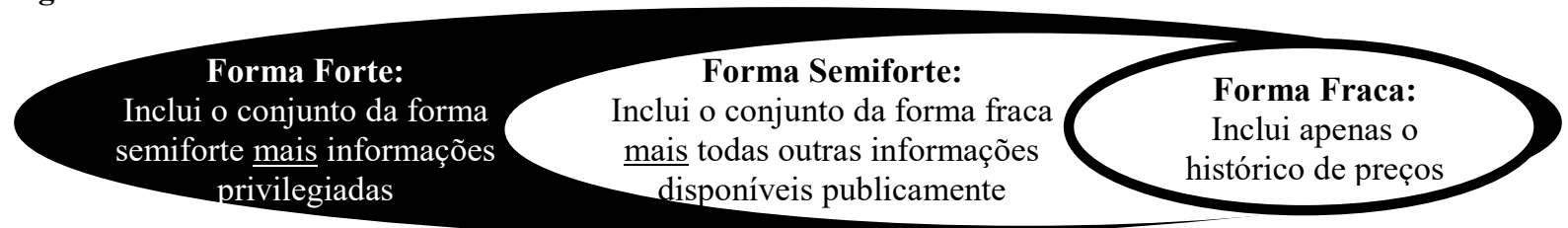

Fonte: Elaboração própria a partir de Fama (1970).

Para Fama (1970), verifica-se que a forma forte de eficiência de mercado pressupõe que todas as informações sobre determinada empresa são conhecidas por todos ao mesmo tempo, mesmo aqueles que teriam acesso à informação privilegiada. Ou seja, o preço da ação reflete toda a informação disponível, seja ela pública ou privada. Assim, os investidores não conseguem obter ganho anormal usando informação privilegiada e isso acontece porque a reação do preço da ação perante novas informações é instantânea e imparcial.

Segundo Fama (1970), percebe-se que a forma semiforte de eficiência de mercado pressupõe que os preços das ações conjeturam todos os dados publicamente disponíveis e que essas informações sobre determinada empresa fluem, mas não tão rapidamente quanto num mercado com forte eficiência. Então a diferença de tempo de atualização da informação pode fornecer uma pequena vantagem ao investidor que tem acesso a ela imediatamente, comparado aos que souberem depois.

A forma fraca de eficiência de mercado pressupõe que as informações são baseadas em valores históricos, o preço da ação só incorpora a performance passada sem considerar, por exemplo, a entrada de novo player no mercado, alguma nova regulação ou mesmo investimentos que a empresa fará em projetos de ganho de produtividade ou no lançamento de um novo produto (FAMA, 1970). Duarte e Pérez-Iñigo (2013) examinaram 371 testes de HEM presentes em 179 pesquisas que contemplam 68 regiões e foram publicadas no Science Direct. Os autores detectaram que 318 pesquisas apresentaram a forma fraca, 50 a forma semiforte e apenas 3 a forma forte de eficiência de mercado. Desse modo, a seguir verificam-se algumas pesquisas sobre a HEM para depois examinar possíveis controversas apontadas nas finanças comportamentais e relacioná-las com essa pesquisa sobre a Kroton.

A HEM mostra evidências favoráveis e controversas em diversas regiões do mundo (JUNIOR; FAMA, 2002; DUARTE; PÉREZ-IÑIGO, 2013). Dessa forma, considerou oportuno verificar algumas pesquisas sobre a eficiência de mercado destacadas no Quadro 1.

Quadro 1: Pesquisas Internacionais sobre Eficiência de Mercado

\begin{tabular}{|l|l|l|}
\hline Autores & Anos & Objetivos e Resultados \\
\hline $\begin{array}{l}\text { Beaver } \\
(1968)\end{array}$ & $\begin{array}{l}1961 \\
\text { a } \\
1965\end{array}$ & $\begin{array}{l}\text { Analisou o conteúdo da divulgação de resultados anuais de 143 empresas, estabelecendo } \\
\text { que tanto o volume de negociações quanto a volatilidade de retorno aumentam no } \\
\text { momento dos anúncios. }\end{array}$ \\
\hline $\begin{array}{l}\text { Ball e } \\
\text { Brown } \\
(1968)\end{array}$ & $\begin{array}{l}1946 \\
\text { a } \\
1966\end{array}$ & $\begin{array}{l}\text { Avaliaram o conteúdo de 17.889 anúncios dos relatórios contábeis de 75 empresas. Os } \\
\text { resultados demonstram que os preços das ações não se ajustam instantaneamente após a } \\
\text { divulgação dos resultados (post earnings announcement drift - PEAD). }\end{array}$ \\
\hline $\begin{array}{l}\text { Foster, } \\
\text { Olsen e } \\
\begin{array}{l}\text { Shevlin } \\
(1984)\end{array}\end{array}$ & $\begin{array}{l}1974 \\
\text { a }\end{array}$ & $\begin{array}{l}\text { Explicaram o retorno ocorrido após as divulgações de resultados de 56.000 observações } \\
\text { nas empresas da The New York Stock Exchange (NYSE) e American Stock Exchange } \\
\text { (AMEX), concluindo que a velocidade de ajuste dos preços das ações não é imediata. }\end{array}$ \\
\hline
\end{tabular}


Quadro 1: Pesquisas Internacionais sobre Eficiência de Mercado

\begin{tabular}{|c|c|c|}
\hline Autores & Anos & Objetivos e Resultados \\
\hline $\begin{array}{l}\text { Bernard e } \\
\text { Thomas } \\
(1989)\end{array}$ & $\begin{array}{l}1974 \\
\mathrm{a} \\
1986\end{array}$ & $\begin{array}{l}\text { Investigaram o conteúdo de } 84.792 \text { dados das empresas da NYSE e AMEX e fizeram } \\
\text { testes em } 15.457 \text { dados do National Association of Securities Dealers Automated } \\
\text { Quotations (NASDAQ). Corroboram com Ball e Brown (1968), e Foster et al. (1984). }\end{array}$ \\
\hline $\begin{array}{l}\text { L'Her e } \\
\text { Suret } \\
(1996)\end{array}$ & $\begin{array}{l}1985 \\
\mathrm{a} \\
1994\end{array}$ & $\begin{array}{l}\text { Examinaram o conteúdo de } 19.885 \text { observações no Canadá e concluíram que a } \\
\text { divulgação da informação influencia as expectativas e modifica os preços das ações. }\end{array}$ \\
\hline $\begin{array}{l}\text { Landsman } \\
\text { e Maydew } \\
(2001)\end{array}$ & $\begin{array}{l}1972 \\
\mathrm{a} \\
1998 \\
\end{array}$ & $\begin{array}{l}\text { Usaram o estudo de Beaver (1968) para examinar o conteúdo da divulgação de resultados } \\
\text { de } 1000 \text { empresas, o resultado corrobora com Beaver (1968). }\end{array}$ \\
\hline $\begin{array}{l}\text { Brav e } \\
\text { Heaton } \\
(2002)\end{array}$ & - & $\begin{array}{l}\text { Comparam as teorias comportamentais com as racionais. Embora os pressupostos das } \\
\text { teorias sejam opostos, as semelhanças matemáticas/preditivas dificultam a distinção. } \\
\text { Observaram que a razão do atraso no ajustamento dos preços das ações após a divulgação } \\
\text { dos resultados está relacionada às incertezas, assimetria das informações e custos de } \\
\text { transação. }\end{array}$ \\
\hline $\begin{array}{l}\text { Carter e } \\
\text { Simkins } \\
(2002)\end{array}$ & 2001 & $\begin{array}{l}\text { Analisaram os preços das ações das } 18 \text { companhias aéreas e } 4 \text { transportadoras de carga } \\
\text { aérea em relação ao ataque terrorista contra os Estados Unidos em } 11 \text { de setembro de } \\
2001 \text { e concluíram que a reação do mercado foi eficiente. }\end{array}$ \\
\hline $\begin{array}{l}\text { Antweiler e } \\
\text { Frank } \\
(2006)\end{array}$ & $\begin{array}{l}1973 \\
\mathrm{a} \\
2001 \\
\end{array}$ & $\begin{array}{l}\text { Verificaram mais de } 250.000 \text { notícias corporativas publicado no Wall Street Journal e } \\
\text { concluíram que o mercado é parcialmente eficiente. }\end{array}$ \\
\hline $\begin{array}{l}\text { Francis et } \\
\text { al. }(2007)\end{array}$ & $\begin{array}{l}1981 \\
\mathrm{a} \\
2001 \\
\end{array}$ & $\begin{array}{l}\text { Analisaram o conteúdo da divulgação de resultados de } 53.326 \text { observações, os resultados } \\
\text { indicam que retorno anormal após a divulgação dos resultados pode estar associado às } \\
\text { incertezas. }\end{array}$ \\
\hline $\begin{array}{l}\text { Shivakumar } \\
(2007)\end{array}$ & - & $\begin{array}{l}\text { Analisa a literatura de HEM. Conclui que os preços das ações não se ajustam } \\
\text { instantaneamente após a divulgação dos resultados devido às incertezas. }\end{array}$ \\
\hline $\begin{array}{l}\text { Erlien } \\
(2011)\end{array}$ & $\begin{array}{l}2007 \\
\mathrm{a} \\
2010\end{array}$ & $\begin{array}{l}\text { Utilizou o estudo de eventos para analisar se há HEM na divulgação de resultados na } \\
\text { Noruega em } 117 \text { empresas da The Oslo Stock Exchange. Constatou que apesar de } \\
\text { pequenos desvios, o mercado é eficiente. A velocidade de resposta às notícias pode estar } \\
\text { relacionada à frequência de negociação e ao estado da economia. }\end{array}$ \\
\hline $\begin{array}{l}\text { Wang e } \\
\text { Phet (2012) }\end{array}$ & $\begin{array}{l}2010 \\
\mathrm{a} \\
2012\end{array}$ & $\begin{array}{l}\text { Utilizaram o estudo de eventos para examinar o impacto da divulgação de resultados no } \\
\text { desempenho do retorno das ações em } 40 \text { das maiores e mais líquidas ações da OMX } \\
\text { Nordic Exchange. Concluíram que a divulgação de informações não foi capaz de } \\
\text { influenciar o mercado de ações de maneira eficiente. }\end{array}$ \\
\hline $\begin{array}{l}\text { Huang e Li } \\
(2014)\end{array}$ & $\begin{array}{l}1995 \\
\mathrm{a} \\
2012\end{array}$ & $\begin{array}{l}\text { Utilizaram o estudo de Beaver (1968) para aplicar em } 38.958 \text { observações de empresas } \\
\text { americanas e } 21.137 \text { observações de empresas chinesas e descobriram que a conclusão } \\
\text { corrobora com Beaver (1968). }\end{array}$ \\
\hline $\begin{array}{l}\text { Duarte e } \\
\text { Pérez-Iñigo } \\
(2014)\end{array}$ & $\begin{array}{l}2002 \\
\mathrm{a} \\
2012 \\
\end{array}$ & $\begin{array}{l}\text { Usaram testes estatísticos para pesquisar a eficiência nos mercados financeiros latino- } \\
\text { americanos e identificaram uma melhora na eficiência de mercado a partir de } 2007 \text { no } \\
\text { México, } 2008 \text { no Brasil e Colômbia, } 2011 \text { no Chile e } 2012 \text { no Peru. }\end{array}$ \\
\hline $\begin{array}{l}\text { Odendaal } \\
(2014)\end{array}$ & $\begin{array}{l}2010 \\
\mathrm{a} \\
2012 \\
\end{array}$ & $\begin{array}{l}\text { Realizou estudo de eventos em } 44 \text { firmas do Financial Times Stock Exchange } 100 \text { (FTSE } \\
\text { 100) em Londres. Apesar de alguns desvios, identificou a HEM na forma semiforte. }\end{array}$ \\
\hline $\begin{array}{l}\text { Beaver, } \\
\text { McNichols } \\
\text { e Wang } \\
(2018)\end{array}$ & $\begin{array}{l}1971 \\
\mathrm{a} \\
2011\end{array}$ & $\begin{array}{l}\text { Beaver, McNichols e Wang (2018) examinam o conteúdo da divulgação de resultados } \\
\text { trimestrais de } 700.000 \text { anúncios, o resultado também corrobora com Beaver (1968). }\end{array}$ \\
\hline
\end{tabular}

Fonte: Elaboração própria a partir de Odendaal (2014) e outras pesquisas em bases de dados.

\subsection{Finanças Comportamentais}

Em Kahneman e Tversky (1979), e Sewell (2007) compreende-se que as finanças comportamentais (FC) são estudos sobre a influência da psicologia no comportamento dos indivíduos de acordo com as informações que esses recebem para a tomada de decisões de investimento e o subsequente efeito nos mercados. Uma das hipóteses mais fortes na teoria de finanças é a ideia da racionalidade do homem nesse processo de tomada de decisões (FAMA, 
1970). Essa hipótese foi criticada e ganhou interesse de pesquisadores desde o início do século XX. Um dos primeiros estudos sobre o assunto foi o livro Psychology of the Stock Market de Selden em 1912, em que ele baseou o livro "na crença de que os movimentos de preços nas bolsas dependem de um grau muito considerável sobre a atitude mental do público investidor e comercial" (SEWELL, 2007, p. 1, tradução nossa).

A teoria de finanças comportamentais surgiu neste cenário, como uma tentativa de aperfeiçoar o modelo moderno de finanças, introduzindo estudos sobre o comportamento e irracionalidade do homem e aplicando conceitos de outras áreas (como psicologia e sociologia) à economia para explicar as decisões financeiras dos indivíduos e aproximar as teorias econômicas e das finanças à realidade dos mercados financeiros (SANTOS et al., 2007, p. 3).

Os precursores de destaque em FC são Kahneman (ganhador do Prêmio Nobel de Economia em 2002) e Tversky. Kahneman e Tversky (1979) pesquisaram sobre o comportamento e a tomada de decisão das pessoas em situações de risco, eles questionaram o pressuposto de racionalidade. Esse tipo de abordagem auxilia a explicar o porquê o mercado em algumas situações pode apresentar ineficiências. Os autores elaboraram um modelo conhecido como Teoria da Perspectiva ou do Prospecto em que constataram que o indivíduo fornece maior peso às perdas do que aos ganhos, tendendo a ser "avesso ao risco para ganhos, mas propenso ao risco para perdas" (JUNIOR; FAMÁ, 2002, p. 28).

Além disso, Kahneman e Tversky (1974) também introduziram alguns conceitos de FC, tais como: representatividade, disponibilidade e ancoragem, que devem ser levados em consideração ao analisar a reação do mercado em relação a divulgação de informações relevantes. A representatividade significa que um desempenho positivo de uma empresa no passado é representativo para que essa continue a ter o mesmo resultado no futuro. Já em relação à disponibilidade, as pessoas de uma forma geral criam uma probabilidade sobre um evento de acordo com as experiências passadas. E na ancoragem, as pessoas fazem estimativas a partir de um valor inicial.

Cabe destacar que Thaler (ganhador do Prêmio Nobel de Economia em 2017) desenvolveu estudos de destaque em FC. Bondt e Thaler (1985) apresentam dois fenômenos comportamentais, são eles: sobre-reação (overreaction) e sub-reação (underreaction). O sobrereação caracteriza-se pelo fato de perdedores passados tornarem-se vencedores futuros, ou viceversa. Já o fenômeno de sub-reação ocorre quando vencedores passados permanecem vencedores no futuro ou perdedores passados continuam sendo perdedores no futuro. Essas características podem implicar em imperfeiçoes na precificação dos ativos, pois nos dois fenômenos as informações relevantes sobre a empresa podem influenciar a tomada de decisão e o resultado pode ser uma super-precificação ou sub-precificação das ações.

Ademais, os "estudos nesta área levam em consideração a natureza humana dos tomadores de decisão no mundo financeiro, os quais, como humanos, estão sujeitos a vieses comportamentais que não poucas vezes os afastam de uma decisão calcada na racionalidade" (JUNIOR; FAMÁ, 2002, p. 26). Para Santos et al. (2011, p. 5), "as emoções e os erros cognitivos podem influenciar o processo de decisão de investidores" e "esses padrões de comportamento podem determinar mudanças no mercado" (SANTOS et al., 2011, p. 5). Esses tipos de pesquisas surgiram a fim de refutar a HEM. Cabe lembrar que defensores das:

Novas Finanças tentam provar que nem sempre os mercados se comportam de forma tão eficiente quanto na teoria, seja em razão da assimetria nas informações, seja porque os tomadores de decisão/investidores não possuem a mesma percepção do risco, ou mesmo por não usarem todos um mesmo modelo de precificação. Isto tudo sem contar com as muitas críticas que surgiram às premissas assumidas nas teorias, consideradas fortes demais (JUNIOR; FAMÁ, 2002, p. 25-26).

Outro fator crítico à HEM está relacionado a existência de comportamentos anormais ou inconsistentes nos preços das ações (BRAV; HEATON, 2002; SANTOS et al., 2007; RICHARDSON; TUNA; WYSOCKI, 2010; NAIKY, 2014) e foram encontradas em "diversos 
estudos e prontamente batizadas de anomalias. As anomalias mais recorrentes registradas em estudos são as anomalias de final de semana e de final de ano" (JUNIOR; FAMÁ, 2002, p. 27). O principal argumento dos defensores da HEM "é que as anomalias identificadas não podem ser generalizadas e não são consistentes ao longo do tempo" (SANTOS et al., 2007, p. 2).

Portanto, não é possível afirmar "se as respostas racionais dos investidores à incerteza da informação ou a seus vieses cognitivos irracionais oferecem uma explicação mais convincente para a existência de anomalias financeiras" (FRANCIS et al., 2007, p. 429, tradução nossa). A rivalidade entre as finanças racionais e comportamentais é mal-entendida como uma "disputa sobre "testabilidade" e "sucesso preditivo". Na verdade, nem as finanças racionais nem as comportamentais oferecem muito em termos de previsões testáveis para melhorar a precisão" (BRAV; HEATON; ROSENBERG, 2004, p.393, tradução nossa). Desse modo, o artigo verifica se o mercado é eficiente ao receber informações relevantes sobre a maior empresa de educação do Brasil listada na B3.

\section{Panorama da Kroton Educacional}

\subsection{Introdução}

Com a finalidade de possibilitar uma análise crítica e direcionada dos resultados e das considerações extraídas dessa pesquisa, considerou-se importante a apresentação de informações para identificação da empresa selecionada, tanto relacionadas ao risco do negócio como ao risco contábil-financeiro da empresa selecionada.

\subsection{Atividade operacional e gestão}

A Kroton (2017a) é a maior empresa privada do mundo no ramo da educação. A gestão da atividade operacional é conduzida por profissionais com vasta experiência adquirida tanto em áreas específicas (ex. recursos humanos, finanças, marketing, logística etc.) quanto no setor da educação.

Foi fundada em 1966 em Belo Horizonte a partir da criação de uma empresa de cursos pré-vestibular chamada Pitágoras, a Kroton (2017b) atua em todos níveis escolares, tais como: pré-escolar, ensino primário e secundário, ensino secundário para adultos, vestibular, cursos livres, educação superior e pós-graduação entre outros. A Kroton tem mais 1,5 milhão de estudantes, com 290.000 estudantes na educação básica em 127 campi e 726 polos divididos entre 11 marcas educacionais que estão distribuídas em todos os estados brasileiros.

A empresa também está envolvida na distribuição, atacado, varejo, importação, e exportação de livros didáticos e revistas entre outras publicações. Além disso, ela licencia produtos pedagógicos relacionados com a escola. A Kroton (2017b) opera 21 campi com a marca Pitágoras; 10 com a marca Unic; 5 com a marca Unopar; e 10 mais com as marcas Unime, Ceama, Unirondon, Fais, Fama e União em 10 estados brasileiros. Ela também opera 804 escolas associadas no Brasil sob a marca Pitágoras, bem como 5 escolas parceiras no Japão e 1 escola parceira no Canadá.

A Kroton (2017b) encerrou o segundo semestre de 2017 com 1,194 milhão de alunos, divididos em 425 mil alunos em ensino superior presencial, 541 mil alunos nos cursos de ensino à distância $(E A D)$ e 228 mil alunos em escolas associadas. Os alunos estão segmentados em 114 unidades de ensino superior presencial $(6,73 \%), 910$ unidades chamadas de pólos de EAD $(53,75 \%)$ e 910 unidades de escolas associadas (39,52\%).

Outro ponto quantitativo é em relação ao Financiamento Estudantil (FIES), que apesar de relevante vem perdendo força conforme demonstram os números, se compararmos o fechamento do segundo trimestre de 2016 com o fechamento do segundo trimestre de 2017, na 
base de graduação total (ensino superior) houve uma queda de 215.773 para 170.903 alunos $(23,7 \%$ para $18,3 \%)$, separando desses números somente a graduação presencial, a queda foi ainda maior (51,6\% para 41,0\%). Segundo estudo da CM Consultoria (2014) o perfil desses alunos de graduação é das classes C e D. O maior custo da Kroton (2017b) está no salário dos professores, no fechamento do segundo semestre de 2016 era $20,80 \%$ e no fechamento do segundo semestre de 2017 foi de 18,50\%.

O perfil dos alunos da Kroton (2017b) é de 62\% de mulheres, sendo este percentual maior no EAD, 59\% dos alunos tem mais de 24 anos, 39\% são casados, $89 \%$ vem de escolas públicas, $80 \%$ tem uma renda familiar menor que $\mathrm{R} \$ 3.520,00$, equivalente à 4 salários mínimos e $76 \%$ estão empregados, $85 \%$ matriculados na graduação e $68 \%$ no EAD, esse último tem sido uma modalidade em expansão que atende as demandas essenciais e universaliza a educação no Brasil (NETO; VALADÃO, 2017).

Um dos objetivos da Kroton (2017b) é a criação de uma disrupção tecnológica. Em 2016 ela investiu cerca de R\$ 96 milhões em inovação e R \$ 207 milhões em qualidade acadêmica. Um dos projetos tecnológicos é a evolução do aprendizado na plataforma tecnológica adaptada em um sistema que oferece as diretrizes de estudo aos alunos. Além deste projeto tem o Canal Conecta, ou seja, um portal de empregos oferecidos para os alunos da Anhanguera por empresas parceiras; o portal digital do aluno e do professor; o modelo de ensino KLS 2.0 (Kroton Learning System) que utiliza o flipped classroom, ou sala de aula invertida, todos estes exemplos visam mostrar o investimento em inovação.

A Kroton (2017b) é a maior empresa brasileira no segmento de ensino superior para o número de alunos e de receita. Em julho de 2014, a empresa fundiu-se com o seu maior rival Anhanguera Educacional convertendo-se na maior empresa de ensino superior do mundo por capitalização de mercado.

Em 01/07/2016 a Kroton (2017b) fez nova oferta para a compra da rede Estácio. O negócio foi avaliado em 5,5 bilhões de reais, porém tal aquisição não foi aprovada pelo Tribunal do Conselho Administrativo de Defesa Econômica (CADE), órgão antitruste brasileiro, por julgar que a operação geraria vários níveis de concentração, inclusive com a formação de monopólios.

\subsection{Desempenho contábil}

Os dados contábeis, mesmo com oscilações no período analisado, mostram que suas políticas de investimento, financiamento e dividendos têm contribuído para a geração de indicadores satisfatórios de liquidez, alavancagem, lucratividade, rentabilidade, expectativa e fluxo de caixa livre mais do que suficientes para cobrir o pagamento das dívidas contratuais.

A Tabela 1 apresenta os índices históricos de desempenho contábil da Kroton.

Tabela 1: Desempenho contábil da Kroton $-{ }^{(*)}$ Valores em Milhares de Reais

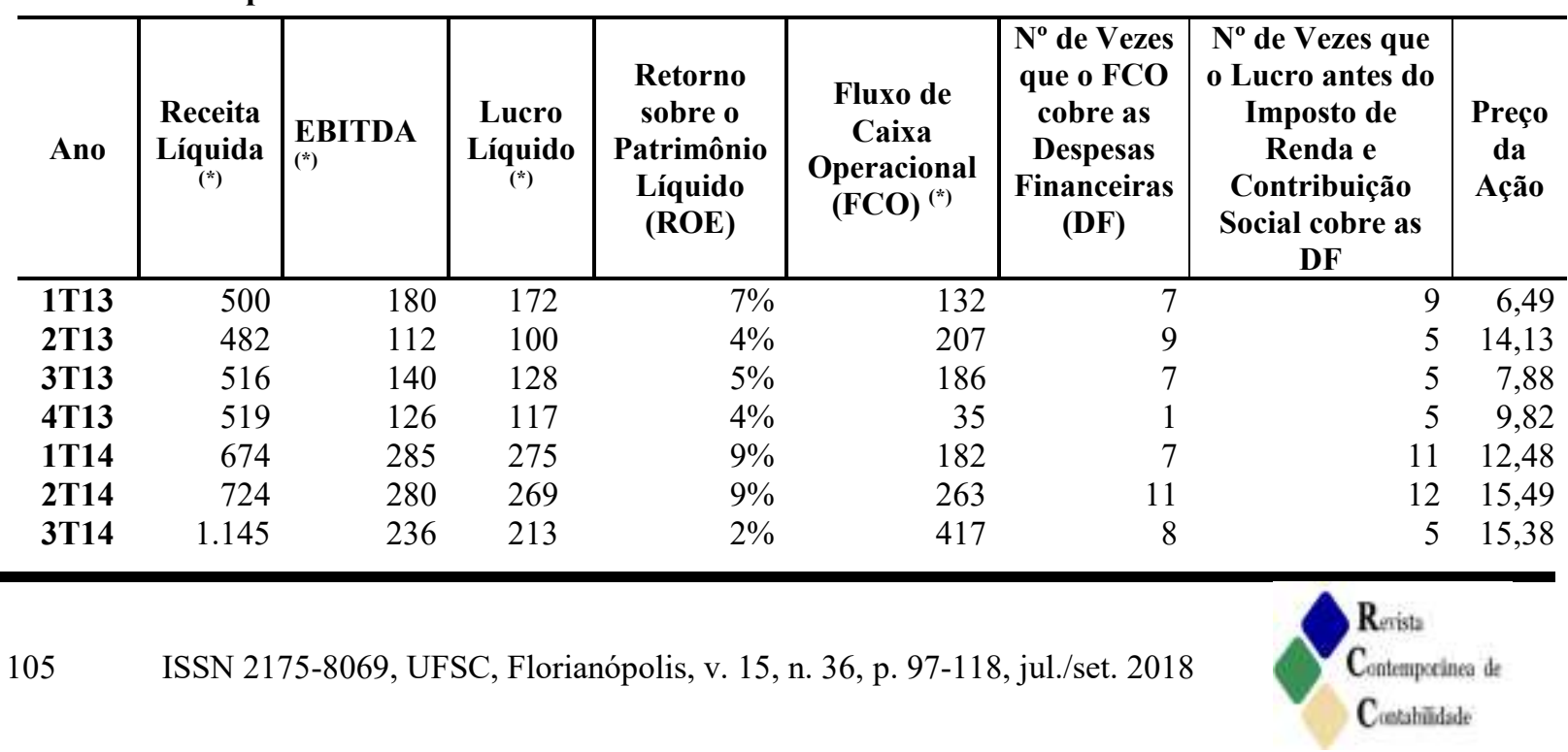


Tabela 1: Desempenho contábil da Kroton $-{ }^{(*)}$ Valores em Milhares de Reais

\begin{tabular}{|c|c|c|c|c|c|c|c|c|}
\hline Ano & $\begin{array}{c}\text { Receita } \\
\text { Líquida } \\
(*)\end{array}$ & $\underset{(*)}{\text { EBITDA }}$ & $\begin{array}{c}\text { Lucro } \\
\text { Líquido } \\
\left(^{*}\right)\end{array}$ & $\begin{array}{c}\text { Retorno } \\
\text { sobre o } \\
\text { Patrimônio } \\
\text { Líquido } \\
\text { (ROE) }\end{array}$ & $\begin{array}{c}\text { Fluxo de } \\
\text { Caixa } \\
\text { Operacional } \\
{\text { (FCO })^{(*)}}^{(*)}\end{array}$ & $\begin{array}{l}\mathrm{N}^{\circ} \text { de Vezes } \\
\text { que o FCO } \\
\text { cobre as } \\
\text { Despesas } \\
\text { Financeiras } \\
\text { (DF) }\end{array}$ & $\begin{array}{c}\mathrm{N}^{0} \text { de Vezes que } \\
\text { o Lucro antes do } \\
\text { Imposto de } \\
\text { Renda e } \\
\text { Contribuição } \\
\text { Social cobre as } \\
\text { DF } \\
\end{array}$ & $\begin{array}{l}\text { Preço } \\
\text { da } \\
\text { Ação }\end{array}$ \\
\hline 4T14 & 1.230 & 240 & 244 & $2 \%$ & 343 & 7 & 4 & 15,5 \\
\hline $1 \mathrm{~T} 15$ & 1.288 & 385 & 372 & $3 \%$ & 63 & 1 & 7 & 10,29 \\
\hline $2 \mathrm{~T} 15$ & 1.411 & 426 & 416 & $3 \%$ & 238 & 5 & 9 & 11,89 \\
\hline 3T15 & 1.235 & 341 & 313 & $3 \%$ & 393 & 8 & 7 & 7,71 \\
\hline $4 \mathrm{~T} 15$ & 1.331 & 344 & 295 & $2 \%$ & 268 & 5 & 7 & 9,53 \\
\hline $1 \mathrm{~T} 16$ & 1.268 & 680 & 599 & $5 \%$ & -21 & 0 & 12 & 11,48 \\
\hline $2 \mathrm{~T} 16$ & 1.391 & 635 & 519 & $4 \%$ & 706 & 16 & 12 & 13,6 \\
\hline $3 \mathrm{~T} 16$ & 707 & 85 & -125 & $-1 \%$ & 580 & 15 & -3 & 14,79 \\
\hline $4 \mathrm{~T} 16$ & 1.879 & 1.231 & 871 & $6 \%$ & 555 & 10 & 16 & 13,33 \\
\hline 1T17 & 1.365 & 551 & 494 & $3 \%$ & 148 & 6 & 21 & 13,28 \\
\hline $2 \mathrm{~T} 17$ & 1.519 & 407 & 547 & $4 \%$ & 565 & 19 & 18 & 14,87 \\
\hline $3 \mathrm{~T} 17$ & 1.323 & 915 & 451 & $3 \%$ & 549 & 29 & 24 & 20,05 \\
\hline
\end{tabular}

Fonte: Elaboração própria a partir de B3 (2017a).

\subsection{Desempenho na bolsa de valores}

A instituição abriu o seu capital em 2007 e de acordo com a B3 (2017b), atualmente apresenta $100 \%$ de ações ordinárias, cujo acionista majoritário é a JP Morgan Asset Management Holdings Inc com apenas 5,36\% de participação na posição acionária com capital diluído e free float de 78,77\% que pode ser considerado satisfatório do ponto de vista da gestão. Apesar de eventuais oscilações de preços (Figura 2), o desempenho bursátil da instituição tem sido favorável desde 2013. Além disso, o mercado é bem pulverizado, na bolsa de valores há apenas cinco empresas no setor.

Figura 2: Comportamento do Preço da Ação por Trimestre/Ano

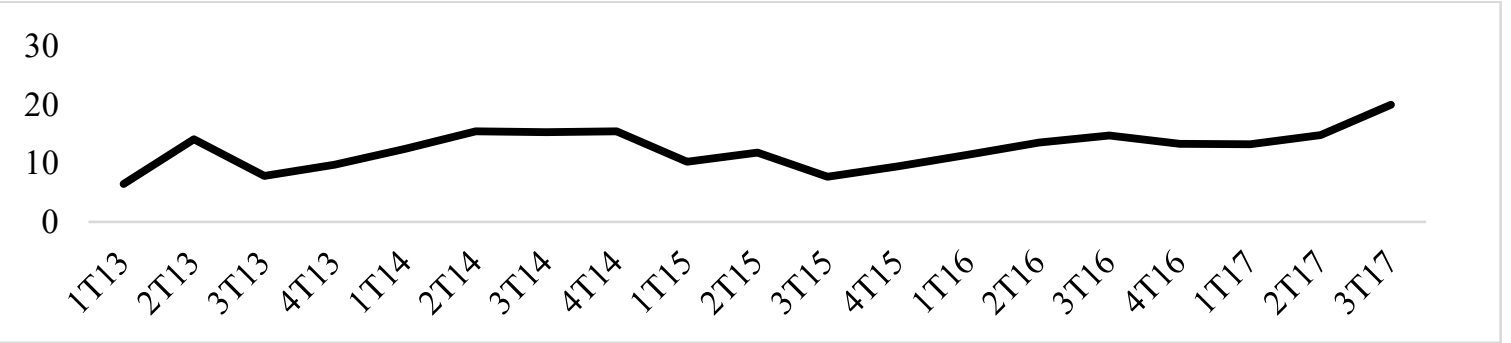

Fonte: Elaboração própria a partir de B3 (2017b).

\subsection{Riscos sistêmicos do setor educacional}

É um setor dependente do governo por causa das regras do FIES. E seus riscos estão relacionados às questões regulatórias relacionadas ao Ministério da Educação (MEC), taxa de desemprego, taxa de juros, reputação, qualidade do ensino, entre outros, que podem causar redução de matrículas, aumento da evasão e inadimplência.

De acordo com o Instituto Brasileiro de Geografia e Estatística (IBGE) (2017), no cenário brasileiro apenas $12,9 \%$ da população total possui ensino superior completo. A meta do Plano Nacional de Educação (PNE) é aumentar a taxa de penetração dos indivíduos, o que 
favorece uma tendência de crescimento para o segmento de instituições de ensino superior no que tange a educação privada e a distância.

Portanto, verifica-se que as perspectivas para o setor e instituição são favoráveis com risco razoável. Além disso, a Kroton (2017b) enxerga oportunidade de crescimento para o setor e por isso planeja algumas metas para o ensino presencial, a distância e educação básica, tais como: novos cursos e polos, melhorias na eficiência, ofertas e experiência do aluno.

\section{Procedimentos Metodólogicos}

Em termos de metodologia do trabalho científico, optou-se por um estudo de caso, pois valida conhecimentos já desenvolvidos por outros autores e corrobora a sua aplicação em um segmento de ensino que começou a despontar recentemente nos mercados de capitais. Segundo Creswell (2010), a natureza da pesquisa é descritiva e a abordagem é mista através da aquisição de indicadores quantitativos e parâmetros qualitativos de avaliação da empresa.

Os dados quantitativos coletados foram os indicadores contábeis, a posição acionária e as cotações supramencionadas verificadas na B3 no período de 2015 a 2017 . No que tange aos dados qualitativos, foram coletadas as informações de setor e riscos; gestão; atividade operacional; clientes; parcerias; fornecedores; tecnologia; perspectivas; metas; fatos relevantes; divulgações de resultados; e comunicados relacionados a Kroton.

Adotar-se-á o método de estudo de eventos para confrontar o comportamento do retorno das ações ordinárias nos períodos ex-ante e ex-post dos eventos selecionados. O objetivo da investigação é analisar se a divulgação de informações relevantes ligadas diretamente a Kroton é imediatamente refletida pelo mercado acionário.

\subsection{Estudo de Eventos}

O estudo de eventos tem uma longa história e talvez a primeira pesquisa sobre o assunto tenha sido a de Dolley em 1933 (MACKINLEY, 1997; CORRADO, 2011), no entanto, Mackinley (1997) é considerado precursor no método e conceitua o estudo de evento como uma metodologia que permite mensurar o efeito de um evento no valor da empresa.

Os "testes procuram mensurar a velocidade do ajustamento dos preços dos títulos ao redor de uma data específica, quando da divulgação de informações relevantes" (CAMARGOS; BARBOSA, 2006, p. 45). O estudo de eventos é uma ferramenta adequada de mensuração que tem por base a HEM, uma vez que os impactos de anúncios relevantes seriam refletidos de maneira rápida no preço das ações (ODENDAAL, 2014; DING et al., 2018). Os procedimentos de estudo de eventos estão representados na Figura 3.

Figura 3: Procedimentos de Estudo de Eventos de Mackinlay (1997)

\begin{tabular}{|c|c|c|c||c||c|}
\hline $\begin{array}{c}\text { Definição } \\
\text { dos } \\
\text { Eventos }\end{array}$ & $\begin{array}{c}\text { Critérios } \\
\text { de } \\
\text { Seleção }\end{array}$ & $\begin{array}{c}\text { Retornos } \\
\text { Normais e } \\
\text { Anormais }\end{array}$ & $\begin{array}{c}\text { Procedimento } \\
\text { de } \\
\text { Estimação }\end{array}$ & $\begin{array}{c}\text { Procedimento } \\
\text { de } \\
\text { Teste }\end{array}$ & $\begin{array}{c}\text { Resultados } \\
\text { Empíricos }\end{array}$ \\
\hline
\end{tabular}

Fonte: Elaboração própria a partir de Mackinlay (1997), e Camargos e Barbosa (2006, p. 49).

Segundo Mackinlay (1997), e Camargos e Barbosa (2006), na primeira etapa de definição dos anúncios, o dia da ocorrência é considerado como a data zero, se o comunicado ocorrer pela manhã, a data zero pode ser a própria data, no entanto, se o comunicado ocorrer após o encerramento do mercado, a data zero pode ser o dia seguinte. Ao redor da data zero é utilizada uma janela de eventos para olhar alguns dias dos períodos ex-ante e ex-post. A janela 
de estimação é composta pelos dias anteriores ao início da janela do evento e a janela de comparação é composta pelas datas posteriores ao dia do evento.

Para Camargos e Barbosa (2006), na segunda etapa de critérios de seleção, no cálculo dos retornos das ações pode ser utilizada as cotações de fechamento diárias e um índice da bolsa de valores para servir de proxie do retorno de mercado. Nessa fase, a amostra é selecionada e se for o caso, a quantidade da amostra pode ser ajustada a fim de evitar sobreposição de eventos, ou seja, "qualquer correlação dos retornos anormais de diferentes títulos, isto é, existência de clustering” (CAMARGOS; BARBOSA, 2006, p. 50).

Em Mackinley (1997), Camargos e Barbosa (2006), Santos et al. (2011), e Camargos e Barbosa (2015) interpreta-se que ao medir os impactos, o estudo de eventos utiliza um método de retorno normal ou esperado que o título apresentaria se o evento não tivesse ocorrido. $\mathrm{O}$ cálculo é realizado com base entre esse retorno esperado e o retorno observado após o acontecimento do evento para analisar se ocorreu um retorno anormal (RA) estatisticamente significativo nos dias anteriores, na data do anúncio e nos dias posteriores ao evento. Esse RA é conhecido como um "desvio no resultado esperado" (SANTOS et al., 2011, p. 6) e pode ser calculado na terceira etapa pela fórmula (CAMARGOS; BARBOSA, 2006): em que:

$$
\text { RAit }=\text { Rit }-E(\text { Rit })
$$

Rit $=$ retorno observado $\mathrm{E}(\mathrm{Rit})=$ retorno calculado pelo modelo; $\mathrm{e} \mathrm{t}=$ tempo do evento.

Cabe destacar que o "fato de a variância dos retornos aumentar próximo à data de divulgação do evento sinaliza que ele contém informações relevantes" (CAMARGOS; BARBOSA, 2006, p. 49) e isso pode servir para detectar se houve a eficiência de mercado no que tange a reação imediata à divulgação do evento. $O$ retorno normal pode ser calculado com a utilização da fórmula logarítmica (CAMARGOS; BARBOSA, 2006): em que:

$$
\text { Ri,nt }=\operatorname{Ln}\left[\frac{\text { Pi,nt }}{\text { Pi,n (t - nt })}\right]
$$

Pi,nt = preço da ação da firma i, no dia t posterior ao intervalo i ocorrido desde a negociação anterior; $\mathrm{Pi}, \mathrm{n}(\mathrm{t}-\mathrm{nt})=$ preço da ação da firma i, no dia $\mathrm{t}$ anterior ao intervalo i ocorrido desde a negociação anterior; e nt = intervalo de tempo decorrido desde a negociação anterior.

$\mathrm{Na}$ quarta etapa do procedimento de estimação pode ser utilizado algum teste de linearidade dos retornos de cada ação com os retornos de um índice da bolsa de valores, adotando-se um critério de exclusão de um nível de significância de uma determinada porcentagem, esse tipo de artifício serviria para tratar os outliers. Na quinta etapa do procedimento de teste, o retorno anormal poderia ser acumulado dentro da janela de evento. A significância estatística dos retornos anormais do período do evento pode ser calculada para testar as hipóteses, analisar a probabilidade de o evento afetar a distribuição normal e identificar se o mercado reagiu à informação. Após essas etapas, podem ser realizadas as interpretações e conclusões (CAMARGOS; BARBOSA, 2006).

Essa pesquisa avaliou os eventos relacionados a divulgação de todos os Fatos Relevantes e todas as Divulgações de Resultados da Kroton, assim como dos Comunicados relacionados às operações de venda e compra de participações e das mudanças ligadas diretamente ao FIES, no período de 30 de setembro 2015 a 30 de setembro de 2017. As "análises de longo prazo em mercados financeiros são importantes para melhor compreensão de fenômenos e validação de achados teóricos" (LIMA; TESTA, 2014, p. 268). O período de dois anos foi selecionado na pesquisa por ter sido o período com o maior número de divulgação de 
Fatos Relevantes da Kroton, no total de 17, e por ter sido o período de tentativa de compra da Estácio, que levou 360 dias, além das mudanças envolvendo o FIES.

O total de divulgações de informações ao mercado observado na pesquisa totalizaram 30 divulgações em 26 dias diferentes. Para melhor avaliação dos eventos e dos retornos apurados na forma individual ou agrupada nas janelas de estimação, de evento e de comparação, quando da existência de retorno anormal, assim como da apresentação dos resultados, os eventos foram separados em três grupos de eventos homogêneos, sendo: Grupo A - Divulgação dos resultados trimestrais, no total de 10; Grupo B - Operações de compra e venda de participações, no total de 18 e Grupo C - Mudanças relacionadas ao FIES, no total de 2 eventos, apresentados nos Quadros 2, 3 e 4.

Quadro 2: Eventos no período de 30/09/15 a 30/09/17 - Grupo A - Divulgação dos Resultados Trimestrais

\begin{tabular}{|c|c|l|}
\hline Data & Tipo de Divulgação & Evento \\
\hline $12 / 11 / 15$ & Divulgação de Resultados & Demonstrações Financeiras do 3o trimestre de 2015 \\
$15 / 03 / 16$ & Divulgação de Resultados & Demonstrações Financeiras do 4o trimestre de 2015 \\
$12 / 05 / 16$ & Fato Relevante & Guidance 2016 \\
$12 / 05 / 16$ & Divulgação de Resultados & Demonstrações Financeiras do 1o trimestre de 2016 \\
$12 / 08 / 16$ & Divulgação de Resultados & Demonstrações Financeiras do 2o trimestre de 2016 \\
$10 / 11 / 16$ & Divulgação de Resultados & Demonstrações Financeiras do 3o trimestre de 2016 \\
$22 / 03 / 17$ & Divulgação de Resultados & Demonstrações Financeiras do 4o trimestre de 2016 \\
$12 / 05 / 17$ & Divulgação de Resultados & Demonstrações Financeiras do 1o trimestre de 2017 \\
$12 / 05 / 17$ & Fato Relevante & Guidance 2017 \\
$11 / 08 / 17$ & Divulgação de Resultados & Demonstrações Financeiras do 2o trimestre de 2017 \\
\hline
\end{tabular}

Fonte: Elaboração própria a partir de Kroton (2017d).

Quadro 3: Eventos no período de 30/09/15 a 30/09/17 - Grupo B - Operações de Compra e Venda de Participações

\begin{tabular}{|c|c|l|}
\hline Data & Tipo de Divulgação & Evento \\
\hline $23 / 10 / 15$ & Fato Relevante & Divulgação na mídia sobre a operação de venda da Uniasselvi \\
$26 / 10 / 15$ & Fato Relevante & Operação de venda da Uniasselvi \\
$29 / 02 / 16$ & Fato Relevante & Conclusão da venda da Uniasselvi \\
$02 / 06 / 16$ & Fato Relevante & Esclarecimento sobre notícia veiculada sobre aquisição da Estácio \\
$21 / 06 / 16$ & Fato Relevante & Carta ao Conselho de Administração da Estácio \\
$01 / 07 / 16$ & Fato Relevante & Combinação dos negócios com a Estácio \\
$08 / 07 / 16$ & Fato Relevante & Protocolo para incorporação de ações da Estácio \\
$14 / 07 / 16$ & Fato Relevante & Incorporação de ações - Assembleia \\
$15 / 08 / 16$ & Fato Relevante & Combinação dos negócios com a Estácio \\
& & Declaração de complexidade do CADE, relativa a operação de aquisição \\
$06 / 12 / 16$ & Fato Relevante & da Estácio \\
& & Situação do Processo de Aprovação pelo CADE, após análise \\
$06 / 02 / 17$ & Fato Relevante & desfavorável na 1a fase do CADE \\
& & Esclarecimento de notícia veiculada na mídia - Troca de correspondências \\
17/03/17 & Fato Relevante & entre Kroton e Estácio \\
$05 / 04 / 17$ & Comunicado ao Mercado & Andamento do Processo de Aprovação pelo CADE \\
$07 / 06 / 17$ & Comunicado ao Mercado & Andamento do Processo de Aprovação pelo CADE \\
$27 / 06 / 17$ & Comunicado ao Mercado & Resposta ao Oficio n ${ }^{\circ}$ 200.2017 da CVM sobre aquisição da Estácio \\
$28 / 06 / 17$ & Fato Relevante & Parecer Negativo do CADE sobre a Operação com a Estácio \\
$28 / 06 / 17$ & Fato Relevante & Programa de Recompra de Ações \\
$31 / 08 / 17$ & Comunicado ao Mercado & Aquisição da FAIR/FAC/FAMAT \\
\hline
\end{tabular}

Fonte: Elaboração própria a partir de Kroton (2017d). 
Quadro 4: Eventos no período de 30/09/15 a 30/09/17 - Grupo C - Mudanças relacionadas ao FIES

\begin{tabular}{|c|c|l|}
\hline Data & Tipo de Divulgação & \multicolumn{1}{c|}{ Evento } \\
\hline 23/01/17 & Fato Relevante & $\begin{array}{l}\text { Esclarecimento de notícia veiculada na mídia - Diferença de preços para } \\
\text { alunos com FIES } \\
\text { Parceria firmada com a BV Financeira (BV) para a oferta de Financiamento } \\
\text { Estudantil Privado (FEP) }\end{array}$ \\
11/08/17 & Comunicado ao Mercado &
\end{tabular}

Fonte: Elaboração própria a partir de Kroton (2017d).

O fato de haver sobreposições de eventos (EDERINGTON; GUAN, YANG, 2015) pode ser uma limitação, pois isso pode gerar um risco de o evento influenciar os retornos (CAMARGOS; BARBOSA, 2006). Quando há sobreposições de eventos, Mackinley (1997) comenta sobre duas formas de lidar com a situação. Uma delas seria considerar o evento anormal agregado num portfólio de eventos dentro de um período determinado, permitindo avaliar a correlação cruzada dos retornos anormais. A outra forma seria fazer a inferência dos eventos sem agregação utilizando um modelo de regressão multivariada com variáveis fictícias na data do evento.

Os eventos divulgados ao mercado no mesmo instante foram agrupados como um único evento, permitindo a avaliação da correlação com os demais eventos agrupados por tipo, principalmente, para fins de identificação dos retornos anormais associados. As informações para análise são as cotações da empresa Kroton verificadas na B3 (2017b) no período em que ocorreram eventos significativos com indicação de impacto direto na cotação das ações da empresa, de acordo com os Quadros 2, 3 e 4.

Os dados coletados são colocados na planilha e é realizado os logaritmos naturais (ln's) para forçar a distribuição normal, calcular os retornos anormais (RA), acumulação de retornos (CAR) e o teste de significância estatística $p$-value ( $\mathrm{p}$-valor) para verificar a probabilidade de o evento afetar a distribuição normal. Se o Beta $(\beta)$ for menor que $5 \%$ há indícios que a informação fornece um impacto relevante no retorno das ações.

A hipótese nula $(\mathrm{H} 0)$ é: $\mathrm{O}$ evento não contribui de forma estatisticamente significativa para os retornos anormais. Enquanto que a hipótese alternativa (H1) é: O evento contribui de forma estatisticamente significativa para os retornos anormais. No cálculo do $\beta$ a janela de estimação contém 50 pregões da KROT3 na B3, os 10 pregões anteriores (a data do evento) são desconsiderados, a fim de evitar efeitos relacionados ao próprio evento. Na Figura 4, a janela de estimação representa o período de dias para o cálculo do $\beta$.

Figura 4 - Esquema Geral das Janelas de Estimação, Evento e Comparação

\begin{tabular}{|c|c|c|c|c|c|}
\hline & Janela de Estimação & & & Janela de Evento & Janela de Comparação \\
\hline$\leftarrow$ & 50 pregões & $\rightarrow \mid \leftarrow$ & 10 pregões & $\rightarrow$ data do evento $\leftarrow$ & 14 pregões \\
\hline
\end{tabular}

Fonte: Elaboração própria.

$\mathrm{Na}$ apuração de observação do p-value é considerado o período de 14 pregões da KROT3 na B3, denominado de janela de comparação. Além do estudo de eventos, foi feita a análise contábil e a avaliação da performance da Kroton para dar aderência ao estudo, o que considera a recomendação feita por Ding et al. (2018) sobre o uso de métodos alternativos para aumentar a robustez da análise do estudo de eventos. A correlação entre a informação divulgada e o efeito no mercado acionário é um resultado esperado.

\section{Resultados}

O estudo de eventos aplicado na pesquisa avaliou o comportamento dos eventos listados nos Quadros 2, 3 e 4 a partir da data da sua divulgação ao mercado. Os resultados apurados foram demonstrados por grupos, conforme Tabelas 2, 3 e 4 . No período analisado de 2 anos, 
foram identificados 10 eventos relacionados à divulgação de resultados, sendo 8 divulgações das demonstrações financeiras, sendo do $3^{\circ}$ trimestre de 2015 ao $2^{\circ}$ trimestre de 2017 , além das projeções para os anos de 2016 e 2017, publicadas simultaneamente à divulgação dos resultados trimestrais, sendo que em nenhum dos eventos individuais ou agrupados foi identificado um retorno anormal, exceto o evento associado à divulgação das demonstrações financeiras do $2^{\circ}$ trimestre de 2017 no dia 11 de agosto de 2017. Neste trabalho a apresentação dos eventos foi realizada em grupos homogêneos, sendo que no dia 11 de agosto de 2017, ocorreram 2 eventos simultâneos. Além da divulgação dos resultados do trimestre, a Kroton divulgou a assinatura da parceria firmada com a BV Financeira (BV) para a oferta de Financiamento Estudantil Privado (FEP).

Tabela 2 - Apuração do p-value nos Eventos Selecionados ao Grupo A - Divulgação dos Resultados Trimestrais e Reação no Período Diário Selecionado

\begin{tabular}{crrrrrrrr}
\hline Período & $\mathbf{1 2} / \mathbf{1 1} / \mathbf{1 5}$ & $\mathbf{1 5} / \mathbf{0 3} / \mathbf{1 6}$ & $\mathbf{1 2 / 0 5} / \mathbf{1 6}$ & $\mathbf{1 2 / 0 8} / \mathbf{1 6}$ & $\mathbf{1 0} / \mathbf{1 1} / \mathbf{1 6}$ & $\mathbf{2 2 / 0 3 / \mathbf { 1 7 }}$ & $\mathbf{1 2} / \mathbf{0 5} / \mathbf{1 7}$ & $\mathbf{1 1 / 0 8} / \mathbf{1 7}$ \\
\hline-5 & 0,201 & 0,689 & 0,974 & 0,370 & 0,777 & 0,018 & 0,713 & 0,654 \\
-4 & 0,346 & 0,491 & 0,915 & 0,129 & 0,518 & 0,037 & 0,832 & 0,512 \\
-3 & 0,277 & 0,436 & 0,694 & 0,128 & 0,287 & 0,262 & 0,983 & 0,576 \\
-2 & 0,410 & 0,399 & 0,556 & 0,035 & 0,680 & 0,170 & 1,000 & 0,611 \\
-1 & 0,273 & 0,622 & 0,813 & 0,108 & 0,974 & 0,368 & 0,995 & 0,437 \\
0 & 0,297 & 0,627 & 0,698 & 0,309 & 0,855 & 0,549 & 0,895 & 0,089 \\
1 & 0,436 & 0,809 & 0,869 & 0,473 & 0,590 & 0,616 & 0,938 & 0,026 \\
2 & 0,517 & 0,867 & 0,880 & 0,611 & 0,569 & 0,555 & 0,862 & 0,007 \\
3 & 0,444 & 0,845 & 0,943 & 0,629 & 0,720 & 0,579 & 0,834 & 0,002 \\
4 & 0,481 & 0,870 & 0,864 & 0,695 & 0,858 & 0,432 & 0,926 & 0,002 \\
5 & 0,562 & 0,667 & 0,736 & 0,706 & 0,740 & 0,451 & 0,905 & 0,016 \\
6 & 0,586 & 0,566 & 0,811 & 0,626 & 0,486 & 0,448 & 0,919 & 0,020 \\
7 & 0,644 & 0,444 & 0,900 & 0,681 & 0,678 & 0,401 & 0,902 & 0,019 \\
8 & 0,555 & 0,716 & 0,800 & 0,666 & 0,724 & 0,410 & 0,971 & 0,029 \\
9 & 0,867 & 0,681 & 0,909 & 0,698 & 0,841 & 0,453 & 0,998 & 0,023 \\
10 & 0,823 & 0,607 & 0,877 & 0,649 & 0,699 & 0,383 & 0,993 & 0,058 \\
11 & 0,776 & 0,567 & 0,877 & 0,599 & 0,831 & 0,228 & 0,964 & 0,136 \\
12 & 0,619 & 0,489 & 0,819 & 0,764 & 0,741 & 0,274 & 0,994 & 0,186 \\
13 & 0,602 & 0,477 & 0,806 & 0,729 & 0,732 & 0,229 & 0,999 & 0,131 \\
14 & 0,511 & 0,460 & 0,356 & 0,680 & 0,772 & 0,257 & 0,977 & 0,114 \\
\hline
\end{tabular}

Fonte: Elaboração própria.

Como demonstrado na Tabela 1, a análise contábil da Kroton, a performance nos 2 primeiros trimestres de 2017 apresentou recuperação, em relação ao mesmo período de 2016, que superou a projeção para o ano de 2017, divulgada em Fato Relevante no dia 12 de maio de 2017, como por exemplo: (i) Crescimento da receita líquida prevista para o ano de 2017 de $5,40 \%$, sendo que no acumulado de 6 meses o crescimento foi de $8,47 \%$ e a Margem Líquida Ajustada prevista para o ano de 2017 de 38,40\%, sendo que no acumulado de 6 meses a taxa foi de 42,36\%, o que é possível verificar no preço da ação da Kroton (2017c), o que reflete uma valorização elevada no período e indica parcialmente a confirmação da HEM. 
Tabela 3 - Apuração do p-value nos Eventos Selecionados ao Grupo B - Operações de Compra e Venda de Participações

\begin{tabular}{|c|c|c|c|c|c|c|c|c|c|c|c|c|c|c|c|c|c|}
\hline \multicolumn{3}{|c|}{ Ano 2015} & \multicolumn{8}{|c|}{$\begin{array}{r}\text { Ano } \\
2016 \\
\end{array}$} & \multicolumn{7}{|c|}{$\begin{array}{l}\text { Ano } \\
2017 \\
\end{array}$} \\
\hline 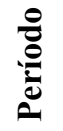 & 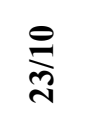 & 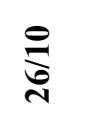 & ๙ิ & ฮి & $\stackrel{\overbrace{}}{\curvearrowright}$ & $\hat{\theta}$ & $\stackrel{\infty}{\ominus}$ & $\stackrel{\hat{g}}{ \pm}$ & $\stackrel{\infty}{\stackrel{\infty}{n}}$ & 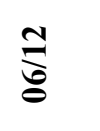 & $\stackrel{̊}{\varrho}$ & $\stackrel{\Re}{\underline{\Sigma}}$ & $\stackrel{5}{\stackrel{2}{8}}$ & $\stackrel{8}{5}$ & 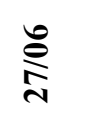 & 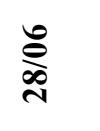 & $\stackrel{\infty}{\stackrel{\infty}{\sigma}}$ \\
\hline-5 & 0,201 & 0,137 & 0,934 & 0,965 & 0,159 & 0,064 & 0,154 & 0,599 & 0,101 & 0,785 & 0,312 & 0,855 & 0,615 & 0,979 & 0,979 & 1,000 & 0,350 \\
\hline-4 & 0,346 & 0,127 & 0,833 & 0,783 & 0,564 & 0,102 & 0,539 & 0,445 & 0,119 & 0,460 & 0,793 & 0,305 & 0,549 & 1,000 & 1,000 & 0,947 & 0,761 \\
\hline-3 & 0,277 & 0,204 & 0,871 & 0,750 & 0,606 & 0,488 & 0,538 & 0,649 & 0,028 & 0,202 & 0,842 & 0,467 & 0,420 & 0,994 & 0,994 & 0,457 & 0,938 \\
\hline-2 & 0,410 & 0,458 & 0,864 & 0,519 & 0,724 & 0,619 & 0,738 & 0,428 & 0,101 & 0,373 & 0,498 & 0,498 & 0,447 & 0,830 & 0,830 & 0,924 & 0,960 \\
\hline-1 & 0,273 & 0,459 & 0,584 & 0,546 & 0,648 & 0,758 & 0,766 & 0,326 & 0,316 & 0,384 & 0,769 & 0,212 & & 0,986 & 0,986 & 0,990 & 0,844 \\
\hline 0 & 0,297 & 0,499 & 0,431 & 0,051 & 0,404 & 0,574 & 0,718 & 0,311 & 0,481 & 0,355 & 0,742 & 0,174 & 0,381 & 0,999 & 0,999 & 0,632 & 0,762 \\
\hline 1 & 0,436 & 0,321 & 0,516 & 0,066 & 0,509 & 0,720 & 0,830 & 0,287 & 0,621 & 0,498 & 0,824 & 0,321 & 0,150 & 0,868 & 0,868 & 0,372 & 0,854 \\
\hline 2 & 0,517 & 0,402 & 0,718 & 0,126 & 0,499 & 0,715 & 0,710 & 0,363 & 0,630 & 0,564 & 0,937 & 0,252 & 0,221 & 0,677 & 0,677 & 0,232 & 0,895 \\
\hline 3 & 0,444 & 0,498 & 0,585 & 0,114 & 0,294 & 0,813 & 0,631 & 0,428 & 0,694 & 0,803 & 0,841 & 0,348 & 0,170 & 0,515 & 0,515 & 0,274 & 0,915 \\
\hline 4 & 0,481 & 0,445 & 0,637 & 0,106 & 0,265 & 0,827 & 0,625 & 0,684 & 0,702 & 0,864 & 0,857 & 0,497 & 0,203 & 0,550 & 0,550 & 0,258 & 0,898 \\
\hline 5 & 0,562 & 0,309 & 0,511 & 0,070 & 0,457 & 0,787 & 0,594 & 0,714 & 0,620 & 0,563 & 0,887 & 0,553 & 0,162 & 0,520 & 0,520 & 0,275 & 0,887 \\
\hline 6 & 0,586 & 0,485 & 0,563 & 0,059 & 0,520 & 0,853 & 0,671 & 0,695 & 0,672 & 0,794 & 0,781 & 0,513 & 0,189 & 0,529 & 0,529 & 0,364 & 0,937 \\
\hline 7 & 0,644 & 0,374 & 0,499 & 0,078 & 0,611 & 0,767 & 0,720 & 0,755 & 0,653 & 0,791 & 0,793 & 0,545 & 0,115 & 0,613 & 0,613 & 0,366 & 0,908 \\
\hline 8 & 0,555 & 0,429 & 0,484 & 0,051 & 0,477 & 0,704 & 0,875 & 0,806 & 0,684 & 0,797 & 0,778 & 0,431 & 0,099 & 0,608 & 0,608 & 0,375 & 0,810 \\
\hline 9 & 0,867 & 0,397 & 0,462 & 0,103 & 0,577 & 0,689 & 0,891 & 0,860 & 0,629 & 0,592 & 0,595 & 0,465 & 0,106 & 0,610 & 0,610 & 0,542 & 0,700 \\
\hline 10 & 0,823 & 0,442 & 0,571 & 0,122 & 0,572 & 0,660 & 0,884 & 0,776 & 0,573 & 0,607 & 0,654 & 0,455 & 0,083 & 0,748 & 0,748 & 0,607 & 0,716 \\
\hline 11 & 0,776 & 0,328 & 0,558 & 0,170 & 0,658 & 0,710 & 0,912 & 0,853 & 0,741 & 0,568 & 0,635 & 0,408 & 0,089 & 0,793 & 0,793 & 0,532 & 0,791 \\
\hline 12 & 0,619 & 0,330 & 0,696 & 0,157 & 0,670 & 0,745 & 0,935 & 0,766 & 0,704 & 0,296 & 0,710 & 0,419 & 0,060 & 0,732 & 0,732 & 0,440 & 0,853 \\
\hline 13 & 0,602 & 0,406 & 0,782 & 0,095 & 0,626 & 0,873 & 0,957 & 0,770 & 0,649 & 0,314 & 0,597 & 0,466 & 0,049 & 0,650 & 0,650 & 0,513 & 0,781 \\
\hline 14 & 0,511 & 0,434 & 0,768 & 0,129 & 0,694 & 0,885 & 0,921 & 0,840 & 0,773 & 0,309 & 0,556 & 0,384 & 0,053 & 0,709 & 0,709 & 0,522 & 0,813 \\
\hline
\end{tabular}

Fonte: Elaboração própria. 
No grupo de eventos associados às operações de compra e venda de participações, não se observou a ocorrência de retorno anormal das ações da Kroton (Tabela 3), o p-value apurado não ficou abaixo de 0,050 , apesar da relevância da operação de aquisição da Estácio. Os principais eventos associados à aquisição da Estácio foram divulgados nos dias 2 de junho de 2016, relativo ao esclarecimento de notícias divulgadas na mídia, e no dia 5 de abril de 2017, relativo ao parecer negativo da operação da Superintendência do CADE, se observou uma maior variação do $p$-value, ainda que não tenha sido estatisticamente significativo.

Tabela 4 - Apuração do p-value nos Eventos Selecionados ao Grupo C - Mudanças Relacionadas ao FIES

\begin{tabular}{crrrrrrrr}
\hline Período & $\mathbf{2 3 / 0 1 / 2 0 1 7}$ & $\mathbf{1 1 / 0 8 / 2 0 1 7}$ & Período & $\mathbf{2 3 / 0 1 / 2 0 1 7}$ & $\mathbf{1 1 / 0 8 / 2 0 1 7}$ & Período & $\mathbf{2 3 / 0 1 / 2 0 1 7}$ & $\mathbf{1 1 / 0 8 / 2 0 1 7}$ \\
\hline-5 & 0,452 & 0,567 & 2 & 0,742 & 0,002 & 9 & 0,713 & 0,011 \\
-4 & 0,159 & 0,57 & 3 & 0,597 & 0,001 & 10 & 0,77 & 0,025 \\
-3 & 0,376 & 0,548 & 4 & 0,533 & 0 & 11 & 0,868 & 0,058 \\
-2 & 0,484 & 0,496 & 5 & 0,701 & 0,004 & 12 & 0,794 & 0,083 \\
-1 & 0,497 & 0,229 & 6 & 0,744 & 0,004 & 13 & 0,812 & 0,043 \\
0 & 0,888 & 0,032 & 7 & 0,583 & 0,007 & 14 & 0,842 & 0,031 \\
1 & 0,753 & 0,012 & 8 & 0,725 & 0,012 & & & \\
\hline
\end{tabular}

Fonte: Elaboração própria.

No grupo de eventos associados às mudanças no FIES, o evento divulgado no dia $11 \mathrm{de}$ agosto, agregado com o evento de divulgação dos resultados do $2^{\circ}$ trimestre de 2017 (Tabela 2 ), apurou-se o p-value abaixo de 0,050, praticamente, em todos os dias da janela de comparação. Os resultados verificados no comportamento no retorno da ação da Kroton de curto prazo, apresentados nos Grupos A e B (p-values > 0,05), indicam reações não significativas do preço da ação imediatamente a divulgação dos eventos selecionados, pressupondo a normalidade no comportamento do retorno das ações. Em parte, isto pode ser explicado pelo histórico de políticas de investimentos em aquisições sinérgicas financiadas por recursos onerosos de longo prazo e por fluxos de caixa mais do que suficientes para cobrir a amortização do serviço da dívida - ver Tabela 1. A reação que, de fato, caracterizou o comportamento de mercado eficiente foi identificada no Grupo C ( $p$-value $<0,05)$, em parte corroborada pelo comportamento ascendente do preço da ação que, a partir da divulgação atinge o maior valor $(\mathrm{R} \$ 20,00)$ - ver Tabela 1 e Figura 2.

Outro fator importante, relativo ao Grupo C, foi a estratégia de financiamento dos alunos com recursos próprios, após a divulgação do governo de redução significativa das verbas do FIES. Para mitigar o impacto dessa informação adversa, a Kroton firmou uma parceria com a BV para a oferta de FEP aos alunos da graduação. Constatou-se na Tabela 4 que, no ato da divulgação e no período ex-post houve retornos anormais das ações entre o $1^{\circ}$ e o $11^{\circ}$ dia, indicando que possivelmente a operação foi tratada internamente pela Kroton com sigilo até a sua conclusão, adicionado a divulgação de resultados positivos acima dos previstos, após o encerramento do insucesso da operação de aquisição da Estácio. Por isso, constatou-se apenas para os eventos selecionados do Grupo $\mathrm{C}$ a rejeição da hipótese nula, que pressupõem que os eventos testados contribuíram de forma estatisticamente significativa para o aumento do preço da ação.

Ao considerar a HEM, o resultado da pesquisa é consistente com os trabalhos de Beaver (1968), Ball e Brown (1968), Foster, Olsen e Shevlin (1984), Bernard e Thomas (1989), L'Her e Suret (1996), Brav e Heaton (2002), Carter e Simkins (2002), Landsman e Maydew (2001), Carter e Simkins (2002), Antweiler e Frank (2006), Francis et al. (2007), Erlien (2011), Huang e Li (2014), Duarte e Pérez-Iñigo (2014), Odendaal (2014), e Beaver, McNichols e Wang (2018), os quais os resultados sugerem que o mercado é eficiente ou parcialmente eficiente (post earnings announcement drift - PEAD). 


\section{Considerações Finais}

Em Fama (1970) percebe-se que a forma semiforte de eficiência de mercado pressupõe que os preços das ações conjeturam todos os dados publicamente disponíveis e que essas informações sobre determinada empresa fluem, mas não tão rapidamente quanto num mercado com forte eficiência. Então a diferença de tempo de atualização da informação pode fornecer uma pequena vantagem ao investidor que tem acesso a ela imediatamente, comparado aos que souberem depois.

O principal objetivo da pesquisa foi a investigação de eventos relacionados à divulgação ao mercado de informações relevantes da Kroton, através do estudo de eventos. Os "testes procuram mensurar a velocidade do ajustamento dos preços dos títulos ao redor de uma data específica, quando da divulgação de informações relevantes" (CAMARGOS; BARBOSA, 2006, p. 45). O resultado verificado neste trabalho rejeita a hipótese nula (Ho) que é: O evento não contribui de forma estatisticamente significativa para os retornos anormais e fornece indícios que confirmam parcialmente a hipótese do mercado eficiente, uma vez que 2 eventos significativos apresentaram oscilações no retorno das ações não refletidas no preço das ações no instante em que ocorreram. No entanto, tendo em vista as diferenças nas políticas de financiamento, dividendos e resultados, as considerações extraídas da pesquisa não devem ser generalizadas para outras instituições.

Dada a atualidade e relevância do tema, propõe-se a continuidade de pesquisas na área de finanças corporativas e de contabilidade, direcionadas as empresas do setor da educação superior de capital aberto. Dentre as lacunas de estudo para complementar ou ajustar os achados dessa pesquisa, recomenda-se a investigação da relação do retorno das ações ordinárias com métricas de avaliação contábil-financeira, como Resultado Operacional (EBITDA), Valor Econômico Agregado (VEA), Valor de Mercado Agregado (VMA), Q-Tobin, Market-to-Book Ratio, Fluxo de Caixa Livre dos Detentores do Capital Patrimonial, etc. Além disso, fatores relacionados as finanças comportamentais, podem influenciar o comportamento dos investidores na data de anúncio de informações relevantes.

O estado da arte com a realização da pesquisa, sustenta-se, em parte, na escassez de estudos acadêmicos com o foco proposto para o setor de educação superior, buscando elucidar o impacto das transformações no setor de ensino superior, notadamente relacionadas a entrada e suporte (gerencial e financeiro) de atores privados de grande porte na composição do capital social das empresas. Ao considerar o dinamismo do mercado acionário, essa pesquisa traz, como contribuição principal, o questionamento de existência de mercado eficiente para os investidores das ações da Kroton, considerando o comportamento do retorno nos períodos exante e ex-post após a divulgação de informações relevantes no período de 2015 a 2017.

Dentre os achados da pesquisa, destaca-se a constatação de que nem todos os investidores agem da mesma forma, analisam as informações a partir de critérios técnicos semelhantes, aplicam o bom senso nas tomadas de decisão ou têm os mesmos interesses. Essa afirmação é corroborada por comportamentos não padronizados do retorno das ações diante da divulgação das informações relevantes selecionadas. A limitação principal desse estudo baseouse na inexistência de pesquisas de mesma natureza para o setor de educação superior. Isto impossibilitou a confrontação de resultados para corroborar ou contestar criticamente os achados da pesquisa.

\section{Referências}

ANTWEILER, W.; FRANK, M. Z. Do US stock markets typically overreact to corporate news stories? News and Market Overreaction, Available at SSRN 878091, aug. 2006. DOI: $10.2139 / \mathrm{ssrn} .878091$ 
Divulgações de informações e o efeito no retorno de ações da maior empresa de educação listada na B3 (Brasil, Bolsa, Balcão)

B3. (2017a). Relatórios financeiros. Disponível em: http://bvmf.bmfbovespa.com.br/ciaslistadas/empresas-

listadas/ResumoDemonstrativosFinanceiros.aspx?codigoCvm=17973\&idioma=pt-br. Acesso em: 24 nov. 2017.

B3. (2017b). Posição acionária. Disponível em: http://bvmf.bmfbovespa.com.br/cias-

listadas/empresas-listadas/ResumoEmpresaPrincipal.aspx?codigoCvm=17973\&idioma=pt-br. Acesso em: 17 nov. 2017.

BAKER, A. C. Single-firm event studies, securities fraud, and financial crisis: problems of inference. Stanford Law Review, v. 68, p. 1207-1266, may. 2016.

BALL, R.; BROWN, P. An empirical evaluation of accounting income numbers. Journal of accounting research, v. 6, n.2, p. 159-178, 1968. DOI: 10.2307/2490232

BEAVER, W. H. The information content of annual earnings announcements. Journal of accounting research, v. 6, p. 67-92, 1968. DOI: 10.2307/2490070

BEAVER, W. H.; MCNICHOLS, M. F.; WANG, Z. Z. The information content of earnings announcements: new insights from intertemporal and cross-sectional behavior. Review of Accounting Studies, v. 23, n. 1, p. 95-135, mar. 2018. DOI: 10.1007/s11142-017-9417-z

BERNARD, V. L.; THOMAS, J. K. Post-earnings-announcement drift: delayed price response or risk premium? Journal of Accounting Research, v. 27, p. 1-36, 1989. DOI: $10.2307 / 2491062$

BONDT, W. F. M. de; THALER, R. Does the stock market overreact? The Journal of Finance, v. 40, n. 3, p. 793-805, jul. 1985. DOI: 10.1111/j.1540-6261.1985.tb05004.x

BRAV, A.; HEATON, J. B. Competing theories of financial anomalies. The Review of Financial Studies, v. 15, n. 2, p. 575-606, 2002. DOI: 10.1093/rfs/15.2.575

BRAV, A.; HEATON, J. B.; ROSENBERG, A. The rational-behavioral debate in financial economics. Journal of Economic Methodology, v. 11, n. 4, p. 393-409, dec. 2004. DOI: $10.1080 / 1350178042000177978$

BRAV, A.; HEATON, J. B. Event studies in securities litigation: low power, confounding effects, and bias. Washington University Law Review, v. 93, p. 583-614, Available at SSRN 2581202, 2015. DOI: $10.2139 /$ ssrn.2581202

CAMARGOS, M. A. de; BARBOSA F. V. Eficiência informacional do mercado de capitais brasileiro pós-Plano Real: um estudo de eventos dos anúncios de fusões e aquisições. Revista de Administração, v. 41, n. 1, p. 43-58, jan./fev./mar. 2006.

CAMARGOS, M. A. de; BARBOSA F. V. Eficiência informacional do mercado de capitais brasileiro em anúncios de fusões e aquisições. Production, v. 25, n. 3, p. 571-584, 2015.

DOI: $10.1590 / 0103-6513.0148$ T6

CAMPBELL, John Y. A variance decomposition for stock returns. National Bureau of Economic Research, Working Paper n. 3246, Available at SSRN 249503, 1990.

CARTER, D. A.; SIMKINS, B. J. Do markets react rationally? The effect of the September 11 th tragedy on airline stock returns. Oklahoma State University, Available at SSRN 306133, april 2002. DOI: 10.2139/ssrn.306133 
CM CONSULTORIA. (2014). Fusões e Aquisições no Ensino Superior - Panorama 2007 2014. Disponível em: http://docplayer.com.br/5607547-Fusoes-e-aquisicoes-no-ensinosuperior.html. Acesso em: 25 set. 2017.

CORRADO, C. J. Event studies: a methodology review. Accounting \& Finance, v. 51, n. 1, p. 207-234, 2011. DOI: 10.1111/j.1467-629X.2010.00375.X

CRESWELL, J. W. Projeto de pesquisa: métodos qualitativo, quantitativo e misto. 3. ed. Porto Alegre: Artmed, 2010.

DING, L. et al. A review of short-term event studies in operations and supply chain management. International Journal of Production Economics, v. 200, p. 329-342, 2018. DOI: $10.1016 /$ j.ijpe.2018.04.006

DUARTE, J. B. D.; PÉREZ-IÑIGO, J. M. M. La eficiencia de los mercados de valores: una revisión. Análisis Financiero, v. 122, p. 21-35, 2013.

DUARTE, J. B. D.; PÉREZ-IÑIGO, J. M. M. Comprobación de la eficiencia débil en los principales mercados financieros latinoamericanos. Estudios Gerenciales, v. 30, n. 133, p. 365-375, 2014. DOI: 10.1016/j.estger.2014.05.005

EDERINGTON, L.; GUAN, W.; YANG, L. Z. Bond market event study methods. Journal of Banking \& Finance, v. 58, p. 281-293, 2015. DOI: 10.1016/j.jbankfin.2015.03.013

ERLIEN, M. Earnings announcements and stock returns - a study of efficiency in the norwegian capital market. 2011. Master thesis (MSc in Business and Economics) University of Stavanger, Norway, jun. 2011.

FAMA, E. F. Efficient Capital Markets. A review of theory and empirical work. The Journal of Finance, v. 25, n. 2, p. 383-417, may. 1970. DOI: $10.2307 / 2325486$

FAMÁ, R.; CIOFFI P. L. de M.; COELHO, P. A. R. Contexto das finanças comportamentais: anomalias e eficiência do mercado de capitais brasileiro. Revista de Gestão USP, v. 15, n. 2, p. 65-78, abr./jun. 2008.

FOSTER, G.; OLSEN, C.; SHEVLIN, T. Earnings releases, anomalies, and the behavior of security returns. The Accounting Review, v. 59, n. 4, p. 574, oct. 1984.

FRANCIS, J. et al. Information uncertainty and post-earnings-announcement-drift. Journal of Business Finance \& Accounting, v. 34, n. 3-4, p. 403-433, april/may 2007. DOI: 10.1111/j.1468-5957.2007.02030.x

GALDI, F. C. et al. Eficiência do mercado de capitais após a adoção da IFRS no Brasil: aplicando o teste de Mishkin. Revista Contemporânea de Contabilidade, v. 14, n. 32, p. 141-156, maio/ago. 2017. DOI: 10.5007/2175-8069.2017v14n32p141

HUANG, Y.; LI, X.. Information content of annual earnings announcements: a comparative study. China Accounting and Finance Review, v. 16, n. 2, p. 171-182, 2014. DOI: 10.7603/s40570-014-0013-3

INSTITUTO BRASILEIRO DE GEOGRAFIA E ESTATÍSTICA (2017). Pesquisa nacional por amostra de domicílios contínua: segundo trimestre de 2017. Disponível em: ftp://ftp.ibge.gov.br/Trabalho_e_Rendimento/Pesquisa_Nacional_por_Amostra_de_Domicilio s_continua/Trimestral/Fasciculos_Indicadores_IBGE/pnadc_201702_trimestre_caderno.pdf. Acesso em: 17 nov. 2017. 
JUNIOR, F. H. F. de C.; FAMÁ, R. As novas finanças e a teoria comportamental no contexto da tomada de decisão sobre investimentos. Caderno de Pesquisas em Administração, v. 9, n. 2, p. 25-35. abr./jun. 2002.

KAHNEMAN, D.; TVERSKY, A. Judgment under uncertainty: heuristics and biases. Science, v.185, n. 4157, p.1124-1131, set. 1974. DOI: 10.1126/science.185.4157.1124

KAHNEMAN, D.; TVERSKY, A. Prospect theory: an analysis of decision under risk.

Econometrica, v. 47, n. 2, p. 263-291, mar. 1979. DOI: $10.2307 / 1914185$

KONCHITCHKI, Y.; O'LEARY, D. E. Event study methodologies in information systems research. International Journal of Accounting Information Systems, v. 12, n. 2, p. 99-115, 2011. DOI: 10.1016/j.accinf.2011.01.002

KROTON. (2017a). Governança corporativa: administração. Disponível em: http://www.kroton.com.br/. Acesso em: 17 nov. 2017.

KROTON. (2017b). Apresentações e Relatórios. Disponível em:

http://www.mzweb.com.br/kroton2010/web/default_pt.asp?idioma=0\&conta=28. Acesso em: 17 nov. 2017.

KROTON. (2017c). Cotações. Disponível em:

http://ri.kroton.com.br/kroton2010/web/conteudo_pt.asp?idioma $=0 \&$ conta=28\&tipo=32847. Acesso em: 17 nov. 2017.

KROTON. (2017d). Documentos CVM. Disponível em: http://www.kroton.com.br/. Acesso em: 06 dez. 2017.

L'HER, Jean-Francois; SURET, Jean-Marc. Consensus, dispersion and security prices.

Contemporary Accounting Research, v. 13, n. 1, p. 209-228, 1996. DOI: 10.1111/j.19113846.1996.tb00498.x

LANDSMAN, W. R.; MAYDEW, E. L. Beaver (1968) revisited: has the information content of quarterly earnings announcements declined in the past three decades? University of North Carolina, Available at SSRN 204068, may 2001. DOI: 10.2139/ssrn.204068

LANDSMAN, W. R.; MAYDEW, E. L. Has the information content of quarterly earnings announcements declined in the past three decades? Journal of Accounting Research, v. 40, n. 3, p. 797-808, 2002. DOI: 10.1111/1475-679X.00071

LIMA, G. A. S. F. de; TESTA, C. H. R. O papel certificador dos fundos de private equity e venture capital sobre a qualidade das empresas estreantes na BM\&FBovespa. Revista de Educação e Pesquisa em Contabilidade, v. 8, n. 3, p. 251-270, jul./set. 2014. DOI: 10.17524/repec.v8i3.1034

LOMBARDI, M. F. S. et al. Competências adquiridas durante o curso de graduação em administração de empresas na ótica dos alunos formandos: um estudo em cinco instituições de ensino superior. Administração: Ensino e Pesquisa, v. 12, n. 1, p. 119-147, 2011. DOI: 10.13058/raep.2011.v12n1.175

MACKINLAY, A. C. Event studies in economics and finance. Journal of Economic Literature, v. 35, n. 1, p. 13-39, 1997.

MALKIEL, Burton G. The efficient market hypothesis and its critics. Journal of Economic Perspectives, v. 17, n. 1, p. 59-82, 2003. DOI: 10.1257/089533003321164958 
MARTIN, K. D.; BORAH, A.; PALMATIER, R. W. Data privacy: effects on customer and firm performance. Journal of Marketing, v. 81, n. 1, p. 36-58, 2017. DOI: 10.1509/jm.15.0497

NAIK, M. R. Study of anomalies in stock market. International Journal of Multidisciplinary Approach \& Studies, v. 1, n. 6, nov./dec. 2014.

NETO, J. da S. C.; VALADÃO, J. de A. D. Evolução da educação superior a distância no Brasil: uma análise a partir de processos de institucionalização. Revista Gestão Universitária na América Latina, v.10, n. 3, p. 97-120, set. 2017.

ODENDAAL, G. R. The impact of earnings announcements on stock prices: an event study for the London Stock Exchange. European Business School London, Available at SSRN 2674594, April 2014.

RICHARDSON, S.; TUNA, I.; WYSOCKI, P. Accounting anomalies and fundamental analysis: a review of recent research advances. Journal of Accounting and Economics, v. 50, n. 2-3, p. 410-454, dec. 2010. DOI: 10.1016/j.jacceco.2010.09.008

RUIZ, R. S. G.; AKÉ, S. C.; MARTÍNEZ, F. V. Una medida de eficiencia de mercado.

Contaduría y Administración, v. 59, n. 4, p. 137-166, oct./dic. 2014. DOI: 10.1016/S01861042(14)70158-5

SANTOS, J. O. dos et. al. Anomalias do mercado acionário: a verificação do efeito segundafeira no Ibovespa, no período de 1986 a 2006. In: CONGRESSO UNIVERSIDADE DE SÃO PAULO: INICIAÇÃO CIENTÍFICA EM CONTABILIDADE, 4, 2007, São Paulo. Anais... Disponível em: http://www.congressousp.fipecafi.org/anais/artigos72007/132.pdf. Acesso em: 18 nov. 2017.

SANTOS, J. O. dos et. al. Análise do impacto de eventos sistêmicos inesperados sobre o preço das ações ordinárias de empresas automotivas japonesas e americanas - Um estudo de caso considerando o recente terremoto no Japão. In: SEMINÁRIOS EM ADMINISTRAÇÃO PPGA/FEA/USP: SEMEAD - ENSINO E PESQUISA EM ADMINISTRAÇÃO, 14, 2011, São Paulo. Anais... Disponível em:

http://sistema.semead.com.br/14semead/resultado/trabalhosPDF/40.pdf. Acesso em: 06 dez. 2017.

SEWELL, M. Behavioural finance. University of Cambridge, 2007.

SHIVAKUMAR, L. Discussion of information uncertainty and post-earnings-announcementdrift. Journal of Business Finance \& Accounting, v. 34, n. 3-4, p. 434-438, april/may 2007. DOI: $10.1111 /$ j.1468-5957.2007.02031.x

WANG, C.; PHET, G. K. Stock return performance around earnings announcements: empirical evidence from Nordic Stock Market. 2012. Master thesis (MSc in Financial Management) - Umeå University, Sweden, 2012. 